\section{Video-assisted two-stage basilic vein transposition for creation of brachio-basilic arteriovenous fistulae}

Editor,

We report our experience in a mixed minimally-invasive technique for the two-stage transposition of basilic vein on a small series of eight patients. The operative technique consisted of a modified endoscopic (1) approach for the two-stage transposition (2). The intervention was performed under Brachial Plexus Block (3).

The basilic vein was first isolated at the cubital fossa of the forearm by means of Miccoli's instruments (Karl Storz Endoskope, Germany) and then the dissection proceeded with a $30^{\circ}$ endoscopic device (Fig. 1 A), normally used for ligation of collateral from the saphenous vein $10 \mathrm{~mm}$ in diameter linked to a camera and a source of cold light. The device has a channel (Fig. 1 B) for the insertion of operative instruments such as the harmonic scalpel (UItracision $^{\mathrm{TM}}$ ). The vein was mobilized by blunt dissection and coagulation under direct view (Fig. 2). In our experience, the use of harmonic scalpel is associated with improved patency rate of the Brachio-Basilic AV fistula and

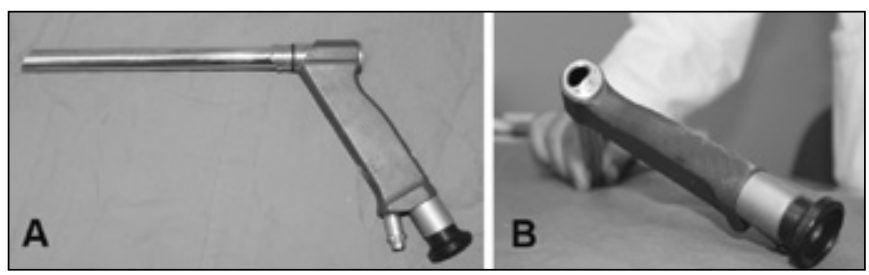

Fig. 1 - A) The device has a handler and a $30^{\circ}$ optical angle $B$ ) The channel for the insertion of harmonic scalpel is visible a decrease in complications related to surgical dissection of the vein with better control of hemostasis, lower risk of vein and median nerve iatrogenic injuries, and reduction in operative time (data not yet published). Small side branches are dissected using absorbable 2/0 ligatures.

The mobilized vein is allocated to a subcutaneous layer pocket created through the fat tissue by means of harmonic scalpel, thus elevating the vein to a more superficial position and closing the aponeurotic fascia above its original bed with an absorbable running suture.

Mean operation time was 120 min (range 90-190).

Some complications such as seroma, subcutaneous hematoma, pain in the forearm the first few days after the operation were treated medically.

Mean hospitalization time was two days.

The primary, assisted-primary, and secondary patency rate at one-year follow-up was respectively: $70 \%, 90 \%$, and $100 \%$, over a period of follow-up of six months, similar to the patency rate reported previously by others authors (1).

All AV fistulas were successfully used for hemodialysis treatment.

In our little experience, the mixed open/video assisted method proposed to perform this type of operation enables obtaining the same results of the open method and decreasing hospital stay and the complications related to surgical wound healing.

The disadvantage of this method is related to prolonged operative time that, although conducted exploiting the advantages of peripheral brachial plexus blockage (3), may cause some discomfort to patients.

In conclusion, this technique appears feasible and reproducible with a reduction in costs in terms of hospital stay and outpatient medications after hospital discharge but taking into account a significant increase in operative time probably because of the low number of cases treated that did not enable developing an optimal learning curve.

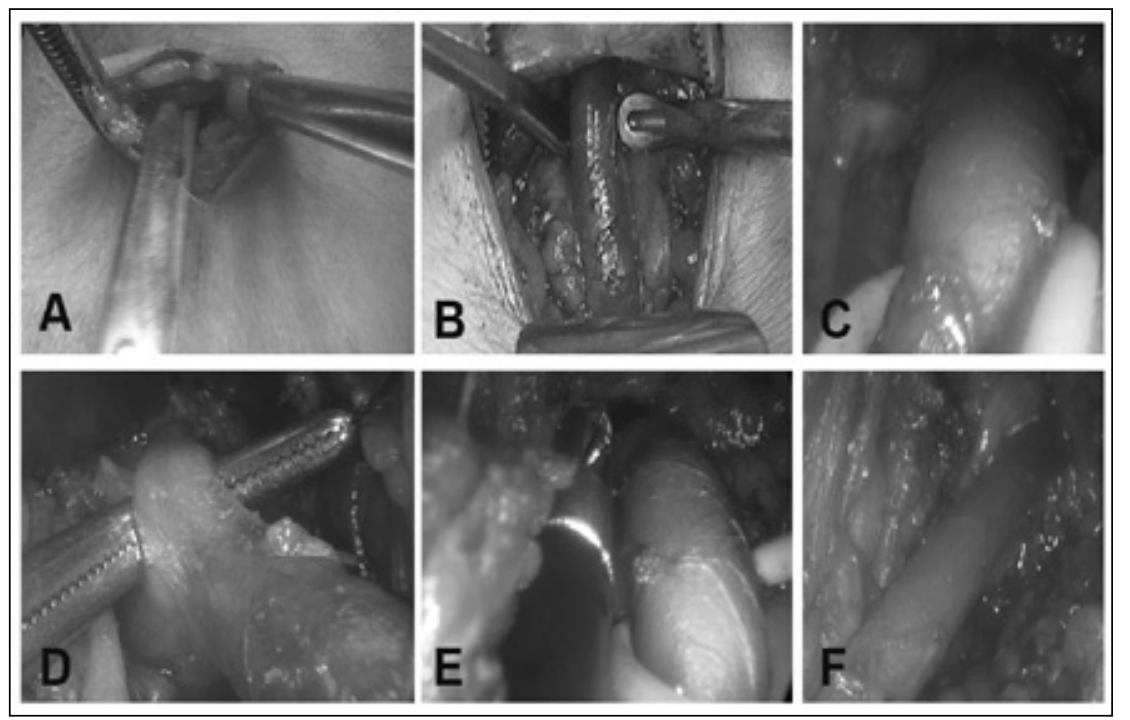

Fig. 2 - A) Small skin incision

$B)$ Initial vein isolation by means of Miccoli's instruments

C) Endoscopic view of arterialized basilic vein

D) Ligature of collateral

E) Harmonic scalpel helps the dissection with optimal hemostasis of operative field

F) Final isolation of basilica vein 


\section{Attilio Ignazio Lo Monte ${ }^{1,2,3}$, Giuseppe Damiano', Vincenzo Davide Palumbo ${ }^{1,2}$, Gabriele Spinelli' Antonino Sammartano", ${ }^{1,}$, Giuseppe Buscemi ${ }^{1,2}$}

${ }^{1}$ School of Medicine, Department of Surgical and Oncologic Disciplines, University of Palermo, Palermo Italy

${ }^{2}$ Department of Surgical and Oncologic Disciplines, Doctorate of Surgical Biotechnoloy and Regenerative Medicine on Organ Failure, University of Palermo, Palermo - Italy

${ }^{3}$ School of Biotechnology, University of Palermo, Palermo - Italy

attilioignazio.lomonte@unipa.it
Conflict of interest: None.

Informed consent: All the patients included in this manuscript consented the use of their personal data for research aims.

\section{REFERENCES}

1. Tordoir JH, Dammers R, de Brauw M. Video-assisted basilic vein transposition for haemodialysis vascular access: preliminary experience with a new technique. Nephrol Dial Transplant. 2001;16(2):391-394.

2. Pasch AR. A two-staged technique for basilic vein transposition. J Vasc Access 2007;8:225-227.

3. Lo Monte AI, Damiano G, Mularo A, et al. Comparison between local and regional anesthesia in arteriovenous fistula creation. J Vasc Access 2011;12(4):331-335. doi: 10.5301/JVA.2011.8560 
Copyright of Journal of Vascular Access is the property of Wichtig Editore and its content may not be copied or emailed to multiple sites or posted to a listserv without the copyright holder's express written permission.

However, users may print, download, or email articles for individual use. 